\title{
EURO-USD PREDICTION APPLICATION USING WEIGHTED MOVING AVERAGE ON MOBILE DEVICE
}

\author{
Afan Galih Salman, Ro'fah Nur Rachmawati and Hendry \\ Computer Science Program, School of Computer Science, Bina Nusantara University, Jakarta, Indonesia
}

Received 2014-02-21; Revised 2014-02-25; Accepted 2014-04-17

\begin{abstract}
Investments in foreign exchange (forex) promise lucrative profits, thus inviting a lot of attention for researcher sand traders to create a system or indicator in trading. All indicators or system is reliable and has proven hat can bring profit for traders. Basically all indicator are reliable and tested which able to bring some profit to traders. Ironically there are many trader fail to gain the profit and became bankrupt. It because they has no well money management and good mentality in trading. Therefore in this study is focused on technical analysis by using weighted moving average which will be implemented on the mobile device so that it can give predictions on the price of the EURO-USD currency pair. The results is the weighted moving average was not quite accurate in determining the price of a currency especially during sideways price but it so accurate when they have strong price trend or large-scale. weighted moving average becomes really easy to apply when using 2 or more weighted moving average and able to give facility in analyzing movement of currency with the counterpart of EURO-USD by means of mobile medium.
\end{abstract}

Keywords: Technical Analysis, Weighted Moving Average, Mobile Device

\section{INTRODUCTION}

Foreign Exchange (Royalforex, 2001) is the exchange of one currency for another or the conversion of one currency into another currency. Foreign exchange also refers to the global market where currencies are traded virtually around-the-clock with the exception of weekends. Unlike money changer where the transaction is made in physical market (with physical commodities and locations), forex transaction is made by transferring fund via bank accounts where the fund is transferred from trader's bank account to other trader's bank account.

Initially Forex is a payment mechanism of trading transaction between countries, due to the requirement of forex keep increase finally forex become the necessity of trading commodities. Forex is the biggest world money market which is measured based on the total transaction value fluctuation with the volume of USD 2 trillions/day whereas the total transaction of the New York stock exchange approximately is only USD 25 million a day.
Therefore forex is classified as high risk-high return investment in financial sector. It means the investment has possibility to gain really high profit up to hundreds per cent per month but associated with high level of potential loss if the investment is not well managed (Yanuar Palimo, 2012). The higher level of risk, the higher level of potential return can be expected (Eko, 2008). The basic principal of Forex is the same as that of trading that is buy when the price is low and sell when the price is high (Endrosiwi, 2008).

There are two analyses of forex that often uses, they are fundamental and technical. The fundamental analysis is an analysis which study economy, strategy, managemen, product, financial condition and other information of the industry or company. Whereas technical analysis is an analysis which study the buyer's emotional condition and they are believe that the hystory will influence the future movement (Venkatesh and Madhu, 2012).

The fundamental analyis stress the importance of the fair value of share and require many data, news and Corresponding Author: Afan Galih Salman, Computer Science Program, School of Computer Science, Bina Nusantara University, Jakarta, Indonesia 
figures. The technical analysis has phylosophy that they able to know the pattern of share's price movement based on observation of share's price movement of the past. The technical analysis is said to be a study on market behaviour that is decribed by a graphic to predict the price trend in the future (Sadeq, 2008).

Technical analysis is divided into two methods that are the classic technical analysis and the modern technical analyisis. The analisis classic technical analysis only rely on the graphical representation of the price action whereas the modern technical analysis also use some. Recently there many indictors that can be used to analyse price movement of share. Every indicator has own nature and characters. Using capability to intrepret the graphic of price movement and assist by indicator, inverstors are expected to be capable of detecting price movement in the future which eventually it facilitate the investor to make right decision.

Euro and USD is money market which offer highly profit and predictable market (Needham, 2010). The predictable market can optimize the level of return investment and reduce the risk (Eko, 2008). EURO and USD are also the biggest market so that this study only discuss the forex trading coverage limited to EURO-USD counterpart exchange.

Basically all indicator are reliable and tested which able to bring some profit to traders. Ironically there are many trader fail to gain the profit and became bankrupt. It because they has no well money management and good mentality in trading. The indicator of Weighted Moving Average (WMA) is a different indicator in the middle axis, meaning it is not too sensitive as exponential moving average and is not too slow in giviving signal as simple moving average. WMA is used in determining a decision to open position buy/sell. In order to facilitate user this application is designed in the basis of android mobile.

\subsection{The Purpose and Benefit}

To fasilitate in analyzing share by mobile Device. As well as providing analysis and prediction of buying and selling by using indicator of weighted moving average.

\section{THE ARCHITECTURE SYSTEM}

The flow chart as seen in Fig. 1 give the steps taken to carry out research on the product development process.

\subsection{Simple Moving Average}

Simple Moving Average (SMA) is a method of finding the average. SMA can be used for determining short term trend, long term trend and seasonal phenomenon (Tsokos, 2010). The formula to calculate SMA:

$$
\mathrm{y}_{\mathrm{t}}=\frac{1}{\mathrm{k}} \sum_{\mathrm{j}=0}^{\mathrm{k}-1} \mathrm{x}_{\mathrm{t}-\mathrm{k}+1+\mathrm{j}}
$$

where, $\mathrm{t}=\mathrm{k}, \mathrm{k}+1, \ldots, \mathrm{n}$.

\subsection{Weighted Moving Average}

Weighted Moving Average (WMA) is a method for finding average by giving the larger weight on the latest data than the weight on the previous data. The latest data weight really depend on the long of the determined period. The longer period that is used the larger weight that will be given on the newest data. Indicator of moving average has excellent prediction with the performance surpassing the more sophisticated prediction technic. Weighted moving average has an advantage that is smoother in determining trend. Weighted moving average is more sensitive than simple moving average so that able to give earlier warning corcerning the change of trend based on the direction of its intersection line (Pring, 2002). Other reseach related with WMA is the Sum of Squares Double Exponentially Weighted Moving Average (SSDEWMA) chart which is effective in detecting shifts in the mean and/or variance is compared with the MaxDEWMA (called the maximum double exponentially weighted moving average) chart (Yin and Chong, 2012).

The formula to calculate indicator of Weighted Moving Average (WMA) is as follow (Roring, 2012):

$$
\mathrm{WMA}=\frac{\frac{\left(\mathrm{nX} \mathrm{n}_{\mathrm{n}}\right)+((\mathrm{n}-1))+\left((\mathrm{n}-2)\left(\mathrm{X}_{\mathrm{n}-2}\right)+\ldots+\left((\mathrm{n}-\mathrm{k})\left(\mathrm{X}_{\mathrm{n}-\mathrm{k}}\right)\right)\right.}{\mathrm{n}+(\mathrm{n}-1)+(\mathrm{n}-2)+\ldots+(\mathrm{n}-\mathrm{k})}}{\mathrm{S}_{\mathrm{n}}}
$$

Where:

$\mathrm{n}=$ The selected periode

$\mathrm{k}=\mathrm{n}-(\mathrm{n}-1)$

$\mathrm{X}_{\mathrm{n}}=$ The subsequent number of data

Weighing value in WMA depends on the long of period which has been determined by us. The longer the determined period the greater value of weigh which given to the current data. Please observe the following Table 1.

Table 1. Calculation of weighted moving average

\begin{tabular}{llcr}
\hline Data & Bobot & Data $\times$ Bobot & WMA 8 Periode \\
\hline 10 & 1 & 10 & \\
11 & 2 & 22 & \\
12 & 3 & 36 & \\
13 & 4 & 52 & \\
14 & 5 & 70 & \\
15 & 6 & 90 & \\
16 & 7 & 112 & \\
17 & 8 & 136 & 528.00 \\
\hline
\end{tabular}




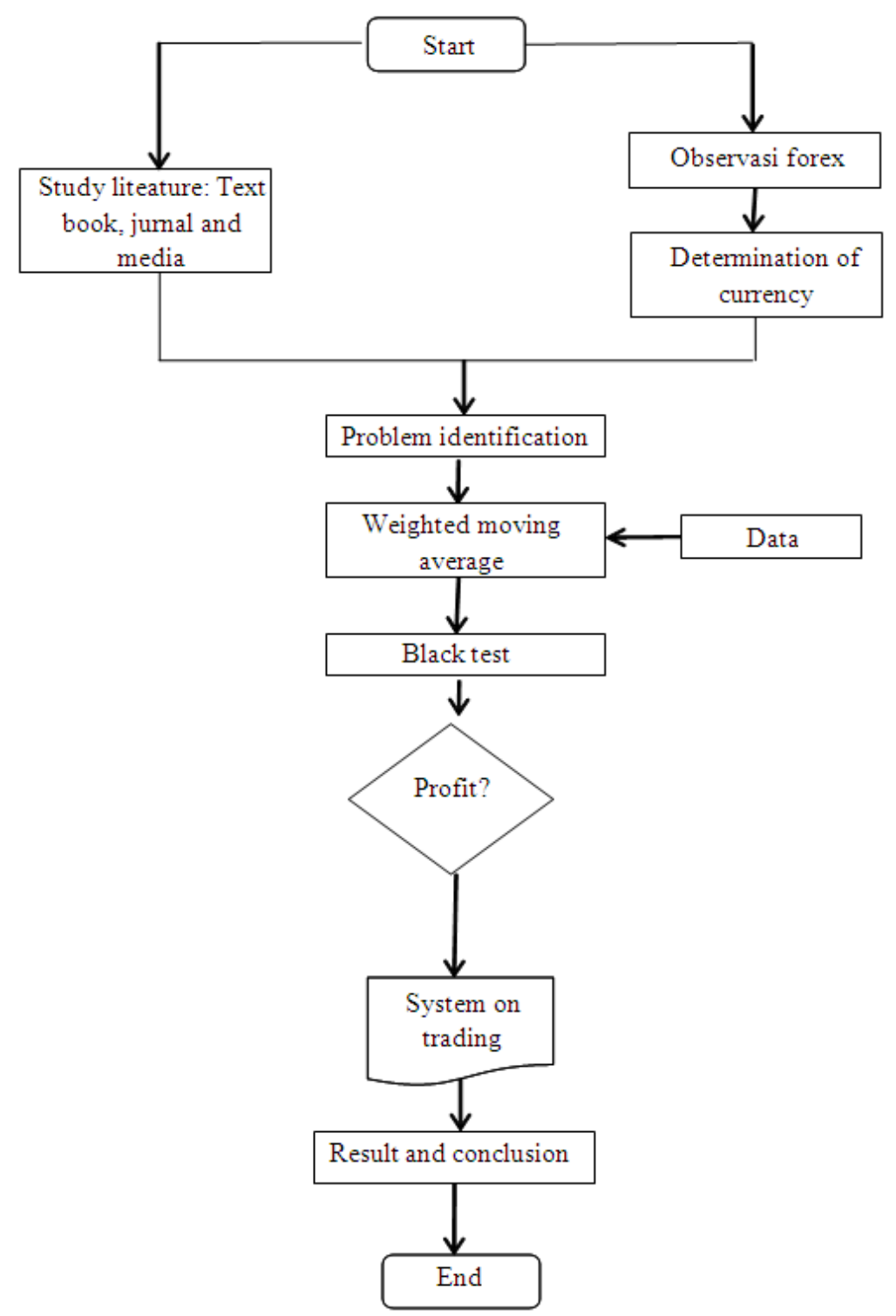

Fig. 1. Methodology

\subsection{Exponential Moving Average}

Exponential Smoothing Moving Average (EMA) is a method for finding average and is one of the forms of indicator which has function for determining trend. The formula of exponential moving average is as follow (Marcelina Rizka Falevy, 2011):

$$
\begin{aligned}
\mathrm{XMA}= & \left(\frac{2}{\mathrm{~N}+1} \times(\text { currentprice }- \text { previous } \mathrm{XMA})\right) \\
& + \text { previous XMA }
\end{aligned}
$$

$$
\mathrm{N} \quad=\text { The long of period. }
$$

current price $=$ The current price.

Previous XMA $=$ The previous value of XMA.

\section{THE DESIGN}

\subsection{Use Case Diagram}

Use case diagram is the whole description of program (Pressman, 2010). Figure 2 shows two actors in the use case diagram: User and Administrator, where user can get information on prediction of foreign exchange and the 
administration has charge of activating foreign exchange analysis so that user can receive information on prediction of foreign exchange as seen if the user chooses "Technical Analyze" then they can see system analysis that has been done in Meta trader which is stored in database. The visible analyses are the trend, the highest price prediction and perceive the rate of EUR USD in every $30 \mathrm{~min}$.

If the user choose pivot then they can see the limit prices which have been made in Meta trader and stored in database. The highest and lowest limit prices (pivot) will be update once in a day, because the limit of daily price does not change in the next hours. The daily limit price only change once in a day.

When the user chooses "Pivot" then user will see the explanation concerning the program content and how to use this mobile application. In this use case there would be explanation regarding each variable along with its functions.

\section{RESULTS}

In order to know the accuracy level of program the "Back Test" shall be done. The Back Test is doing analysis with the data derived from the past. This program use the data that derived start from 2012.03.01 00:00 to 2013.03.29 20:00. The accuracy of program is shown in Fig. 2.

The Fig. 3 above is the result from calculation of three moving average. The blue line is the price line, the green line is the line that is derived from calculation using weighted moving average, the red line is the line that is derived from calculation using Simple Moving Average and the purple line is the line that is derived from calculation using exponential moving average. The above graphic obviously shows that on the date of 1906-2013 weighted moving average touched the price line subsequently following by the line of Exponential Moving Average and Simple Moving Average. On the date of 31-7-2013 the lines of weighted moving average touched the price line following by the lines of simple moving average and exponential moving average. Observing the result we can conclude that the weighted moving average give the warning earlier than other methods concerning the change of trend so that it able to maximize the profit.

Examples of display application on mobile device shown in Fig. 3 and 4.

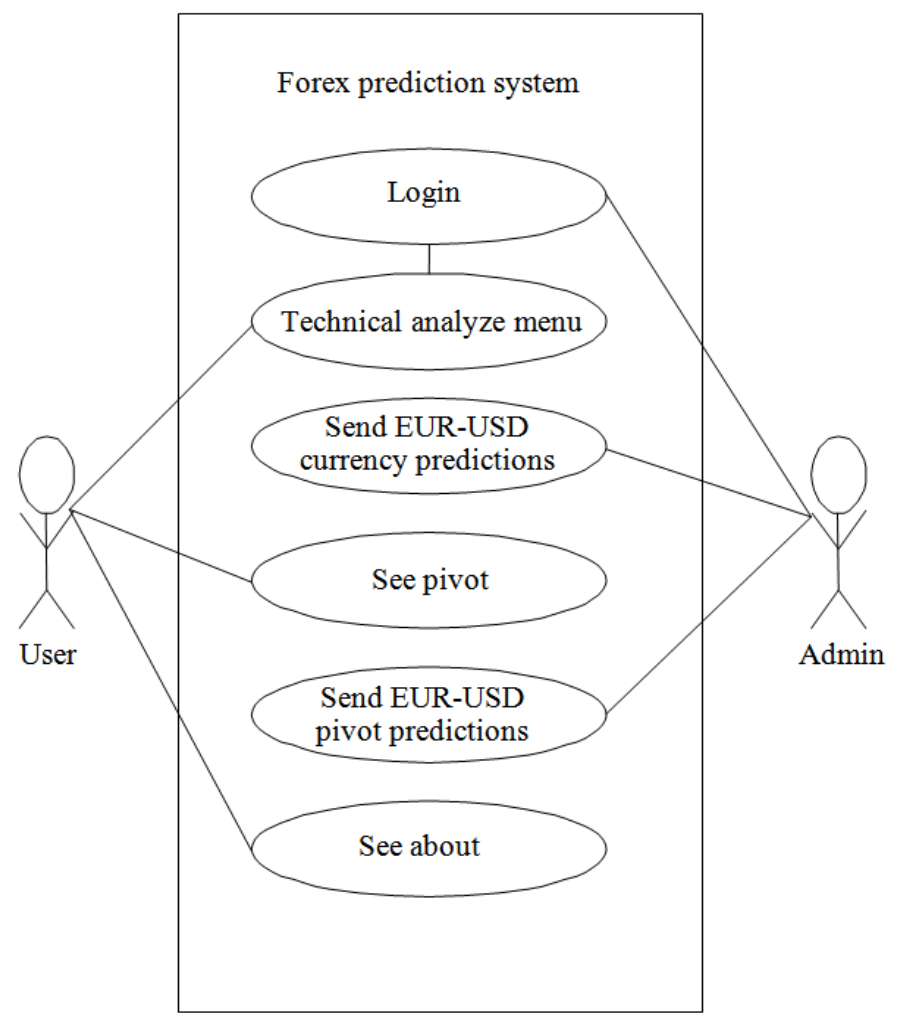

Fig. 2. Use case diagram 


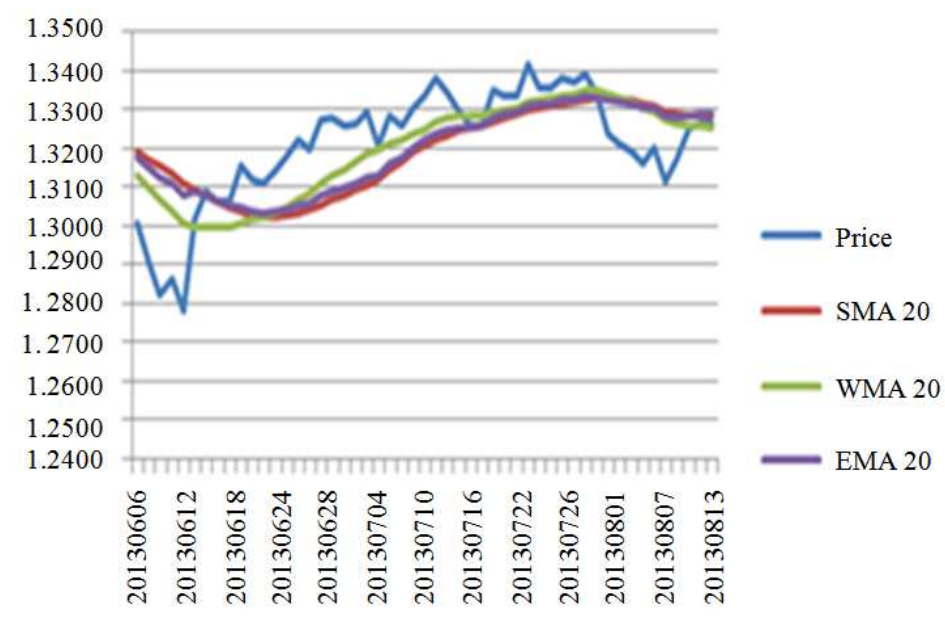

Fig. 3. The result from calculation of three moving average
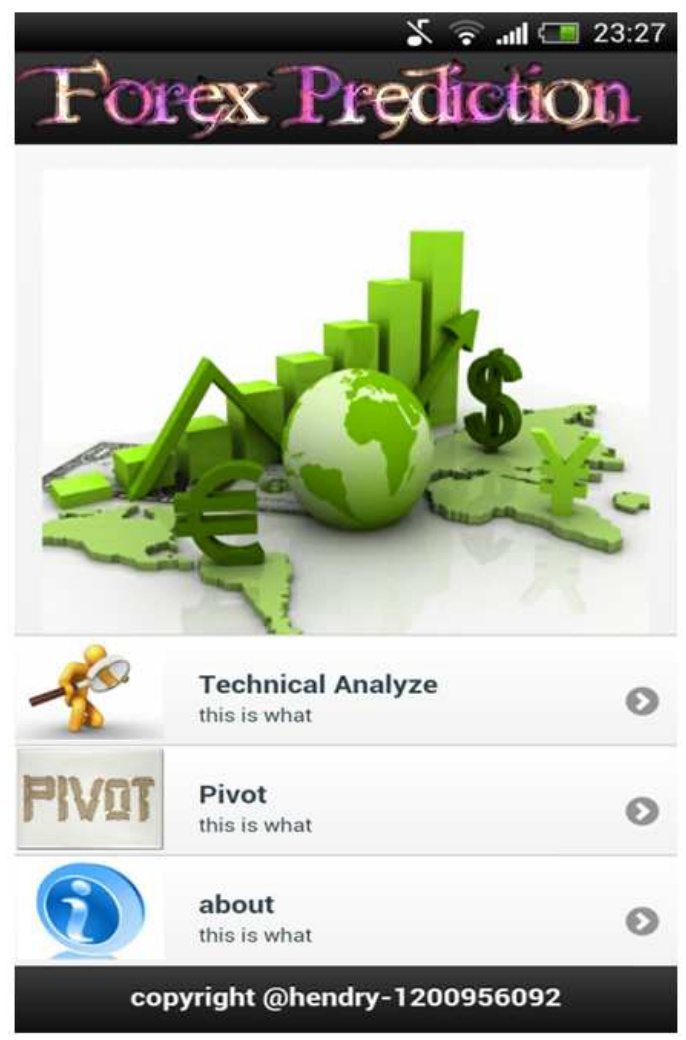

Fig. 4. Main menu

\section{CONCLUSION}

Based on the analysis of designing and implementing The Foreign Exchange Prediction Application resulting in the following conclusion.

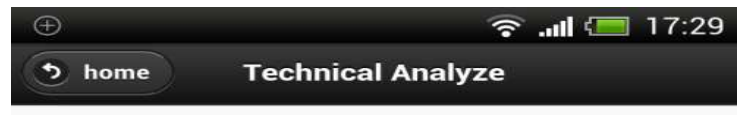

2013-07-10 23:52:38

\begin{tabular}{|l|l|}
\hline \multicolumn{2}{|c|}{ Prediction } \\
\hline Pair & EURUSD \\
\hline Ask & 1.2823 \\
\hline Bid & 1.282 \\
\hline Signal & SELL \\
\hline Price In & 1.3042 \\
\hline Take Profit & 1.3002 \\
\hline Stop Loss & 1.3076 \\
\hline Rate & good \\
\hline
\end{tabular}

copyright @hendry-1200956092

Fig. 5. Technical analyze

Observing from Fig. 5 We can conclude that the weighted moving average give the warning earlier than other methods concerning the change of trend so that it able to maximize the profit. This matters strengthens the previous study that the technical analysis is an analysis which study the graphic in order to know how the buyer's emotion and history influence the exchange rate 
movement in the future (Venkatesh and Madhu, 2012) also strengthens other technical analysis on market behavior that described by graphic to predict the trend of price in the future (Sadeq, 2008).

It turn out that weighted moving average is not accurate enough in determining the currency price trend of EURO-USD counterpart especially in condition of sideway price but the trend determination is really accurate when the price trend is strong or in the condition of large scale.

Weighted moving average becomes really easy to apply when using 2 or more weighted moving average.

This Forex Prediction application able to give facility in analyzing movement of currency with the counterpart of EURO-USD by means of mobile medium.

The limitations of the research are: Only only focus on analyzing euro-US dollar exchange rate, applied data of euro-US dollar exchange rate is derived from metatrader 4 , prediction is made only to assist the trader in decision making. It is not a fixed price and analysis is performed based on indicator of weighted moving average.

he future research prospects are: Develop this application to be a means that able to give notification to the user, use more than one indicator and add price prediction for various of currency pair.

\section{REFERENCES}

Eko, U., 2008. Analisis dan penilaian kinerja portofolio optimal saham-saham LQ-45. BISNIS Birokrasi J., 15: $178-187$.

Endrosiwi, A., 2008. Forex Itu Mudah: Panduan Forex Untuk Orang Biasa. Kampusforex.

Marcelina Rizka Falevy, M.S., 2011. Sistem peramalan harga sembako berbasi moving average dengan brew platform sebagai mobile interface. Surabaya: ITS.
Needham, J., 2010. The currency wars of 2010. Forex J.

Pressman, R.S., 2010. Software Engineering: A Practitioner's Approach. San Fransisco: Mc Graw Hill.

Pring, M.J., 2002. Technical Analysis Explained: The Successful Investor's Guide to Spotting Investment Trends and Turning Points. 4th Edn., McGraw-Hill, Singapore, ISBN-10: 0071816194, pp: 560.

Roring, R., 2012. Analisis peramalan volatility harga saham di ihsg dengan indikator bollinger bands dan stochastic oscillator. Binus University.

Royalforex, 2001. Forex: Study Book For Successful Foreign Exchange Dealing. 1st Edn., Royal Forex, Los Angeles.

Sadeq, A., 2008. Analisis prediksi indeks harga saham gabungan dengan metode arima (studi pada IHSG di bursa efek Jakarta). Semarang.

Tsokos, P.C., 2010. K-th moving, weighted and exponential moving average for time series forecasting models. Eur. J. Pure Applied Math., 3: 406-416.

Venkatesh, C.K. and T. Madhu, 2012. The use of fundamental and technical analysis by stock exchange dealers: Indian evidence. J. World Econ. Rev., 7: 117-126.

Yanuar Palimo, A.B., 2012. Perbandingan efisiensi teknikal indikator simple moving average dan exponential moving average pada saham pertambangan batubara di bursa efek Indonesia. Depok: Universitas Gunadarma.

Yin, T.S. and M.K.B. Chong, 2012. A study on the effects of non-normality on the performances of Max-DEWMA versus SS-DEWMA charts. J. Math. Stat., 8: 57-63. DOI: 10.3844/jmssp.2012.57.63 